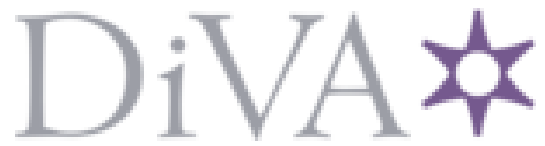

http://www.diva-portal.org

This is the published version of a paper published in Catena (Cremlingen. Print).

Citation for the original published paper (version of record):

Rahmati, O., Kalantari, Z., Ferreira, C S., Chen, W., Soleimanpour, S M. et al. (2022)

Contribution of physical and anthropogenic factors to gully erosion initiation

Catena (Cremlingen. Print), 210: 105925-105925

https://doi.org/10.1016/j.catena.2021.105925

Access to the published version may require subscription.

N.B. When citing this work, cite the original published paper.

Permanent link to this version:

http://urn.kb.se/resolve?urn=urn:nbn:se:kth:diva-308427 


\title{
Contribution of physical and anthropogenic factors to gully erosion initiation
}

\author{
Omid Rahmati $^{\text {a }}$, Zahra Kalantari ${ }^{\text {b,c }}$, Carla Sofia Ferreira ${ }^{\text {b, d,e }}$, Wei Chen ${ }^{\mathrm{f}}$, \\ Seyed Masoud Soleimanpour ${ }^{\text {g, *, Marijana Kapović-Solomun }}{ }^{\text {h, }}$, Samaneh Seifollahi-Aghmiuni ${ }^{\text {b }}$, \\ Navid Ghajarnia ${ }^{b}$, Nader Kazemi Kazemabady ${ }^{i}$ \\ ${ }^{\text {a }}$ Soil Conservation and Watershed Management Research Department, Kurdistan Agricultural and Natural Resources Research and Education Center, AREEO, Sanandaj, \\ Iran \\ b Stockholm University, Department of Physical Geography and Bolin Centre for Climate Research, SE-106 91 Stockholm, Sweden \\ ${ }^{\mathrm{c}}$ Department of Sustainable Development, Environmental Science and Engineering (SEED), KTH Royal Institute of Technology, SE-100 44 Stockholm, Sweden \\ ' Navarino Environmental Observatory, 24001 Messinia, Greece \\ ${ }^{\mathrm{e}}$ Research Centre for Natural Resources, Environment and Society (CERNAS), College of Agriculture, Polytechnic Institute of Coimbra, Coimbra, Portugal \\ ${ }^{\mathrm{f}}$ College of Geology and Environment, Xi'an University of Science and Technology, Xi'an 710054, China \\ ${ }^{\mathrm{g}}$ Soil Conservation and Watershed Management Research Department, Fars Agricultural and Natural Resources Research and Education Center, Agricultural Research, \\ Education and Extension Organization (AREEO), Shiraz, Iran \\ ${ }^{\mathrm{h}}$ Department of Forest Ecology, Faculty of Forestry, University of Banja Luka, Republic of Srpska, Bosnia and Herzegovina \\ ${ }^{i}$ Faculty of Natural Resources Management, Ferdowsi University of Mashhad, Mashhad, Iran
}

\section{A R T I C L E I N F O}

\section{Keywords:}

Soil erosion

Modeling

Geo-environmental factors

Artificial intelligence

GIS

\begin{abstract}
A B S T R A C T
Losses of large volumes of soil through gully formation lead to serious environmental, societal, and economic problems for human societies. This study establishes a framework based on an artificial intelligence approach to investigate the impact of geo-environmental and topo-hydrological factors on gully occurrences in the Biram region, Iran. The maximum entropy, random forest, and boosted regression trees machine-learning models were applied. The relative importance of variables (RIV) was then determined and gully erosion susceptibility maps were generated. Model results were evaluated using cutoff-dependent and -independent metrics. All models identified road construction as the main cause of gully formation in the study region (RVI ranged between $27 \%$ and 34\%), and a medium contribution of distance from stream (RVI $=15-18 \%)$, lithology (RVI $=12-15 \%)$ and land use (RVI $=8-12 \%)$. Other factors such as drainage density, topographic wetness index, aspect, slope, profile curvature, elevation and plan curvature showed lower relative importance (RIV $<10 \%$ ). Planners should pay attention to minimizing gully erosion along roads, so that river systems and downstream communities are adequately protected.
\end{abstract}

\section{Introduction}

Gully erosion causes in-site and downstream environmental degradation. Human activities in arid and semi-arid areas accelerate gully occurrence that alters Earth's landscapes and affects humanenvironmental sustainability (Lesschen et al., 2007; Garosi et al., 2018). Usually gully erosion is known as anthropogenic alteration of landscapes, resulting in a serious threat to global agricultural sustainability through loss of productive capacity (Vanwalleghem et al., 2017). Since gullies can be a large source of watershed sediment yield, they negatively affect water quality (Wang et al., 2020). Siltation of drainage network and reservoirs, and damage to transport networks and infrastructure are consequences of intense gully erosion (Fox et al., 2016). Furthermore, gullies may lead to negative socio-economic consequences, driven by damage to infrastructure and transport routes (e.g., roads and rail routes), and siltation of reservoirs. Nearly $41 \%$ of the Earth's surface covered by arid and semi-arid environments, and comprising is 2 billion inhabitants, is sensitive to gully erosion (MEA, 2005). Huge soil losses from permanent gullies have been reported around the word. For example, $56 \mathrm{t} \mathrm{ha}^{-1} \mathrm{y}^{-1}$ in Norway (Oygarden, 2003), $207 \mathrm{tha}^{-1} \mathrm{y}^{-1}$ in Spain (Martínez-Casasnovas et al., 2002), $330 \mathrm{t}$ $\mathrm{ha}^{-1} \mathrm{y}^{-1}$ in southern Morocco (Peter et al., 2014), and $1550 \mathrm{tha}^{-1} \mathrm{y}^{-1}$ in

\footnotetext{
* Corresponding author.

E-mail address: m.soleimanpour@areeo.ac.ir (S.M. Soleimanpour).
} 

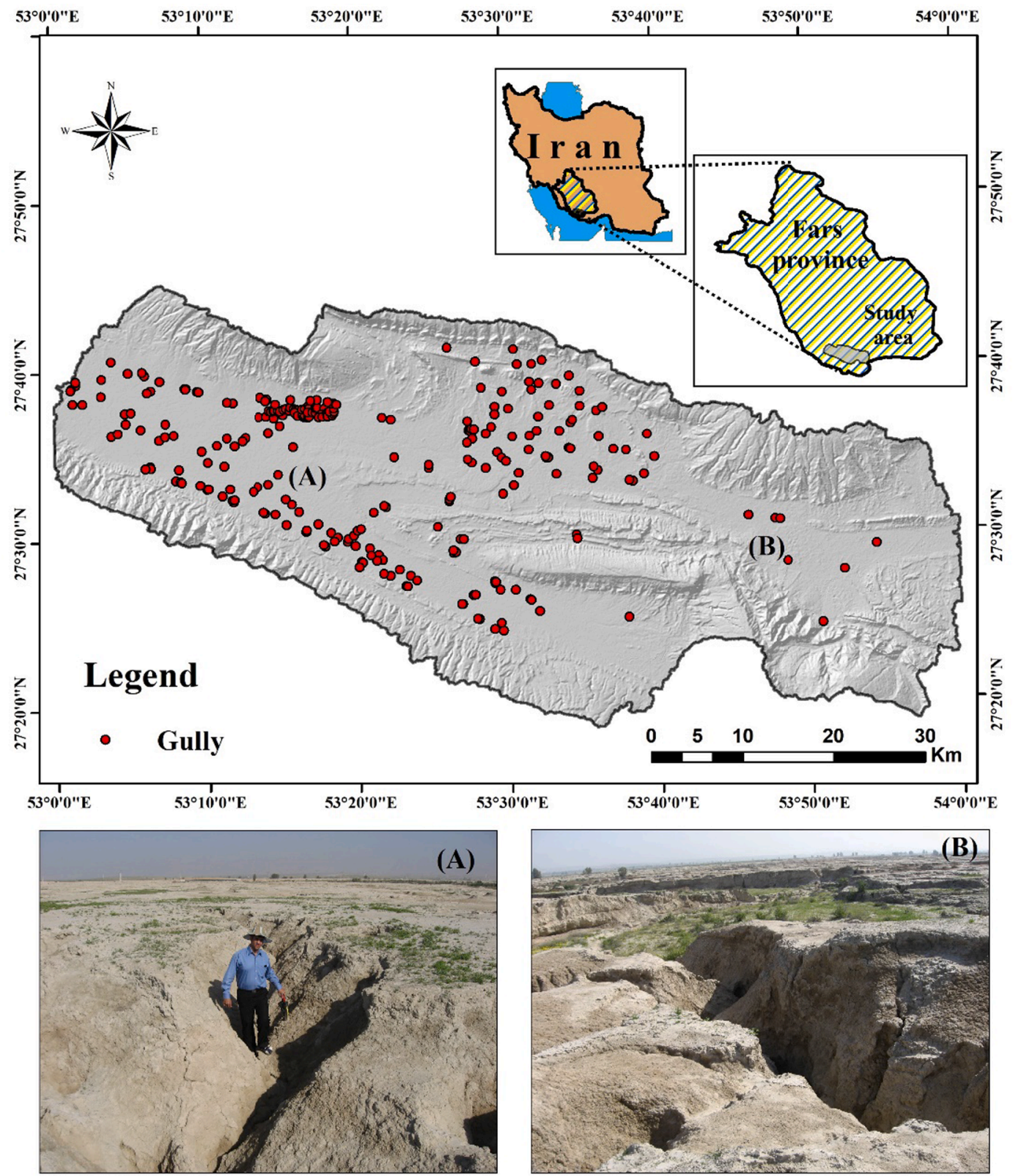

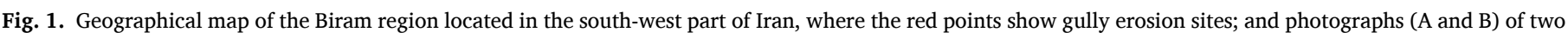

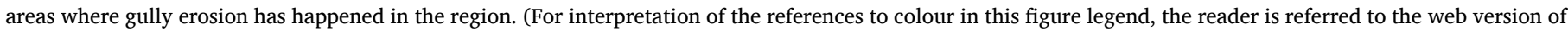
this article.)

New Zealand (De Rose et al., 1998). In semi-arid and arid regions, gully erosion contributes up to $70 \%$ of all transported sediments (Bewke and Sterk, 2003; Zhao et al., 2013). Thus, it is critical to identify triggering factors of gully formation and determine land predisposition to gully erosion in semi-arid regions.

Gully formation processes are dynamic and regulated by a broad variety of features (Castillo and Gómez, 2016). Although commonly triggered or accelerated by climate events (e.g., extreme rainfall leading to high runoff or droughts which decimate protective vegetation), most gully erosion is driven by land use changes and unsustainable human activities, due to their impact on drainage and infiltration conditions. Human activities are an inherent part of the earth system that affect geomorphological and hydrological processes, although their consequences in the subfield of gully erosion are not yet understood. In the Anthropocene period, gully erosion is becoming a ubiquitous phenomenon, particularly on agricultural land, driven by: overgrazing of rangelands (Valentin et al., 2005); intensive farming systems which reduce soil organic matter and soil structural stability; and irrigation drainage systems (Valentin et al., 2005). In forest land uses, gullying is driven by wildfires (Galang et al., 2010), deforestation (Gholami, 2013), and construction of access infrastructure (Croke and Mockler, 2001), since they damage vegetation cover and thus facilitate gully erosion (Castillo and Gómez, 2016). Gullies have been also observed in urbanized and developed environments, mainly due to soil compaction, construction activities, and unlawful habitations without adequate municipal infrastructure (e.g., roadways and sanitation facilities) (Guerra, 2004). The initiation of gullies is often linked to the road construction and other axial runoff conveyors (e.g., lanes or tracks), since they receive and concentrate runoff from larger surfaces and thus influence the development and geometry of gullies (Imwangana et al., 2014). Therefore, different factors controlling and influencing the development of gullies, such as topography, physical properties of soil, lithology, climate, rainfall, and land use need to be considered for gully erosion assessment.

Several attempts have been made to investigate the contribution of 


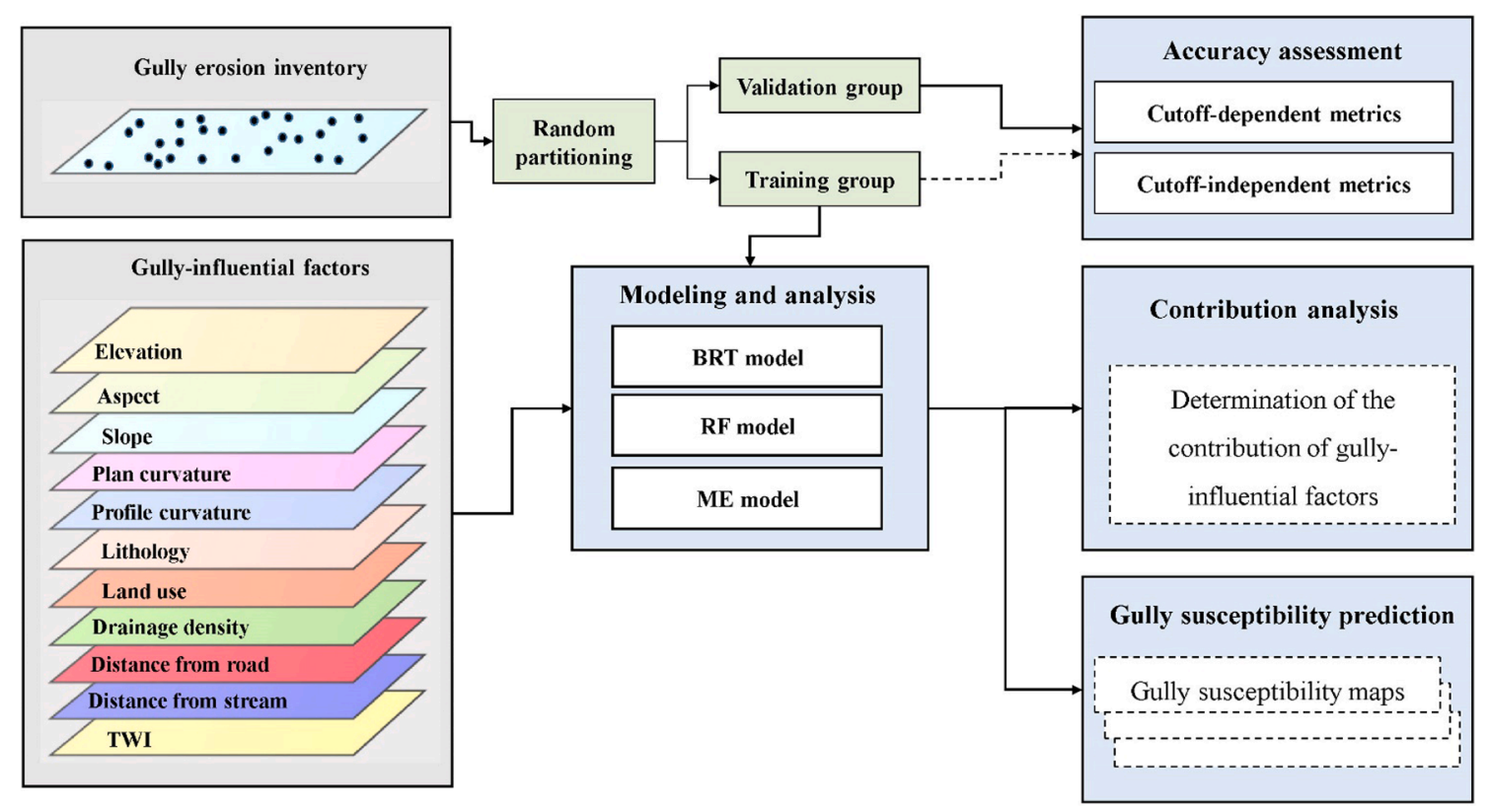

Fig. 2. Flowchart of the methodological approach used in the study.

natural and anthropogenic factors to gully occurrence. For instance, Samani et al. (2010) determined the influence of factors on gully formation using a multiple regression. Bergonse and Reis (2016) applied a regression method to scrutinize the role of different factors potentially affecting the location of large gullies in Portugal. In addition, Mararakanye and Sumner (2017) assessed the influence of factors contributing to gully erosion using the information value (InfVal) statistics in the Mpumalanga province of South Africa. Rahmati et al. (2017) used a conditional probability (CP) model for identifying the spatial relationship between gullies and the geo-environmental factors. However, statistical methods need the classification of each factor and this procedure may provide uncertainties. The impact of contributing factors to gully erosion has not yet been investigated using machine learning models. On one hand, a full understanding of complex and long-term interactions between human activities and the natural geomorphodynamic processes needs powerful artificial intelligence techniques (Suman et al., 2016). On the other hand, gully erosion should be assessed and interpreted on the basis of its historical occurrences, to provide a deeper insight on gully causative factors, drivers, and their effects (Vanwalleghem et al., 2017). The groundbreaking contribution of this study is to elucidate the integrated relationships of gully causative factors and gully events across a semi-arid region through novel machine learning models. The main objectives are to: (i) quantify the level influence of different anthropogenic activities and geo-environmental factors contributing to gully formation; and (ii) produce precise gully erosion susceptibility maps to support local land management plans. This research offers problem-solving lessons to better understand human-environment interactions for gully erosion controlling.

\section{Study region}

The Biram region, in the south part of Fars province in south-western Iran $\left(27^{\circ} 10^{\prime}-27^{\circ} 50^{\prime} \mathrm{N} ; 53^{\circ} 00^{\prime}-54^{\circ} 00^{\prime} \mathrm{E}\right)$ was considered as the study region (Fig. 1). The area of the region is approximately $2957.3 \mathrm{~km}^{2}$, and its elevation varies between 400 and $2150 \mathrm{~m}$. It has a semi-arid climate characterized by hot summers as well as cold winters. Long-term mean annual precipitation in this region is around $248 \mathrm{~mm}$, based on meteorological station data (1986-2019). Although the region is rural, with a population of 2900 people, it is close to major urban areas and populated centers, such as Lar and Lamerd. Land use types of the study region include residential areas (0.69\%), dry-farming $(0.05 \%)$, orchard $(0.03 \%)$, forest $(0.07 \%)$, rangeland $(68.3 \%)$, bare land $(28.27 \%)$, agricultural land (2.59\%).

The region was selected for study, because of its susceptibility to land degradation by gully erosion as a result of various human interventions, including road construction to provide services and goods to rural communities (Fig. 1). Roads in the region follow the general pattern of providing access to residential areas (Fig. 1), but their increase has changed the runoff concentration pattern and maximized soil erosion by water. As regards socioeconomics, local people's income comes from producing goods through dryland agricultural activities and traditional livestock grazing, enhancing human disturbances in the study region and favoring soil and land degradation through gully erosion, recorded over past decades. In addition to high erosion potential, there are economic challenges in terms of budget allocation conflicts involving the public and private sectors, highlighting the necessity and importance of developing a map which shows regional susceptibility to gully erosion. Accurate gully susceptibility mapping helps to communicate the locations where management strategies are necessary.

\section{Methodology}

The methodological workflow applied in this study is shown in Fig. 2, and described in detail in the following sub-sections. Two input variables were used in the modeling step: gully inventory data (dependent variable) and geo-environmental maps (independent variables). Artificial intelligence approach was used to scrutinize the importance level of independent variables (also termed predictor factors) for gully formation. After evaluating the accuracy of the models using two metrics, gully erosion susceptibility maps were generated and the contribution of different influencing factors to gully formation were explored.

\subsection{Gully inventory and splitting of dataset}

A gully inventory map includes historical gully events and thus contains some important and unique information on the distribution pattern of gully erosion features, so it helps understand the gullying process and relationships with influencing factors. Therefore, generating an accurate gully inventory dataset is one of the basic steps in spatial modeling of gully erosion susceptibility. In this work, a gully erosion 
inventory map of the study region was generated using aerial photographs, google earth, and available reports obtained from the Natural Resource Organization of Fars province. Abundant ground-truth data were collected from multiple field surveys to validate the gully dataset. The geographical location of gullies was recorded using a global positioning system (GPS) receiver. The gully erosion inventory map produced in 2019 included 268 gullies.

Spatial modeling using machine learning models always needs two sample groups, for model training and validation (Conoscenti et al., 2014). The gully dataset was randomly partitioned and the models were built with 188 data points $(70 \%)$ and validated with the remaining 80 data points (Fig. S1).

\subsection{Factors influencing gully formation}

In recent decades, gully erosion occurrence in the Mediterranean region has been successfully predicted by applying different numerical and data mining approaches (Bou Kheir et al., 2007; Conoscenti et al., 2014). In those studies, physical factors including topography, soil properties, lithology, and man-made factors including land use were used as independent variables. In addition to these commonly used factors, the present study also included the distance to roads as another man-made factor, and five additional geotechnical-environmental and topographical-hydrological factors which possibly cause gully occurrence in the study region: drainage density, plan and profile curvatures, river network, and index of topographic wetness (TWI). The current status of the 11 factors considered in the present study are shown in Fig. S2 (see Fig. S2 in the supplementary information file).

Rapid population growth, especially in developing countries, usually leads to deforestation, occupation of rangeland, and cultivation of hillsides with no conservation measures. Improper irrigation design, expansion of agricultural activities to uplands, and overgrazing result in significant land cover changes (Hassen and Bantider, 2020), and accelerate the natural gullying process (Valentin et al., 2005). Soil organic matter reduction due to years of intense farming reduces soil structural stability and resilience to crusting, and concentrates flow-based gully erosions (Valentin, 2004). The main land cover in our study region consists of mostly bare land and rangeland (Fig. S2). Some agricultural land is located near dispersed rural communities, but is not concentrated in a specific location nor dominant in the study region. Dryland farming $(0.05 \%)$, orchards $(0.03 \%)$, and planted forests $(0.07 \%)$ occupy minimal land in the study region.

Roads are constructed in residential areas to support various human activities and enable the supply of goods and services to those areas. Road construction results in concentrated runoff as a critical factor exacerbating soil erosion in bare land and rangeland (Seutloali et al., 2016). Expansion of impervious surfaces, combined with vegetation removal, changes the storing and distributing capacities of water across the land and generates overland runoff with high frequency and magnitude (Shellberg et al., 2016). This enhances gully development (Nyssen et al., 2002), which explains the consideration of distance from road infrastructure in this study as a man-made factor influencing gully erosion. In Fig. S2, roads are shown in dark red (associated with zero distance from road) and sites farthest from a road (max. $\sim 17.3 \mathrm{~km}$ in the study region) are shown in green.

Topography determines the erosive power of overland runoff and plays a key role in initiation and expansion of gully erosion (GómezGutiérrez et al., 2015). It also defines the drainage area of a catchment, and thus affects the volume and velocity of overland runoff. In this study, topography was characterized by two factors, elevation and slope (Fig. S2). The central and western parts of the study region are flat, with a varying elevation ranging from 400 to $700 \mathrm{~m}$, while the north-eastern and south-eastern parts are mountainous, with elevation ranging from 402 to $2154 \mathrm{~m}$ (Fig. S2). Slope influences the velocity of runoff and the opportunities for it to infiltrate into the landscape. Low overall land slope greatly increases the storage capacity of ploughed ridges and bunds, thereby reducing the risk of runoff. The steepest slopes (up to 73\%) in the study region are in the mountainous parts (Fig. S2). Based on slope, a map of aspect, which determines the dominant direction of runoff flow, was developed for the study region (Fig. S2). In central, southern, and western sites of the region, the dominant aspect is to the north $(\mathrm{N})$, while in the north-west, north, and some central parts water flows predominantly to the north-east (NE) and south (S).

Plan curvature is usually defined as the contour line curvature which is formed as an intersection of a horizontal plane and the surface (Wilson and Gallant, 2000). It was another factor taken into account for the assessment of gully development in the study region that describes the change on slope in inclination or aspect (Nefeslioglu et al., 2008). Positive (Negative) values in plan curvature layer refer to convexity (concavity) of slope curvature, whereas plan curvature of a flat surface is considered as zero. The value of this factor ranges between -10.9 and 8.13 in the study region (Fig. S2). Profile curvature is defined as the surface curvature to the direction of the steepest slope (in the vertical floe line), and was also considered in this study. This factor changes the velocity of water flow that drains the surface and affects erosion and sediment deposition. In contrast to plan curvature, positive (negative) values of profile curvature indicate concavity (convexity) of slope curvature. Erosion prevails in locations that have negative profile curvature, while positive curvature favors deposition. The value of this factor in the study region changes between -11.32 and 12.08 (Fig. S2).

Drainage density was another factor considered in this study as the total stream length per a unit area in the study region and depends on lithology, permeability, vegetation cover, and soil type (Moeini et al., 2015). This factor can help determine the rate of soil erosion in different catchments. The values of drainage density in the study region changes between $0.1 \times 10^{-3}\left(\mathrm{~km} / \mathrm{km}^{2}\right)$ to $1.4 \times 10^{-3}\left(\mathrm{~km} / \mathrm{km}^{2}\right)$, and is lower in the mountainous (marginal) parts and higher in central parts (Fig. S2). Another relevant factor evaluated in this study for its impact on development of gully erosion was distance from stream, which was calculated based on the stream network (Fig. S2).

Pattern and rate of gully development are highly correlated with soil/lithological properties (Luca et al., 2011), since materials have different ranges of shear strength and hydraulic conductivity. Tectonically induced compressional and tensional forces play an important role in landform patterns (Planchon et al., 1987) and cause fractures and cracks in rocks. In addition, different geological time scales affect the properties of soil, solid bedrock, and rock type in landscapes. Weak soil/ rock structures are more sensitive to erosion by water flow, and their locations in a landscape can become concentration sites for surface flow, and thus initiate gully erosion. In the study region, 11 types of bedrocks were identified based on a geological-map at 1:25000-scale, developed using ArcGIS 10.3 (Fig. S2). The map showed the dominant proportions of piedmont fan and valley terrace deposits (lithological unit Qft2) in the study region, as listed in Table S1.

The final factor being investigated for its contribution to gully erosion in the study region was the index of topographic wetness (TWI) (Zhu et al., 2014). TWI is a quantification of the tendency for the capacity of soil for water distribution, mainly affected by topography, and shows a high correlation with soil moisture (Radula et al., 2018), highlighting its potential contribution to initiation of gully erosion. In the study region, TWI changes from 0.9 to 22.1 with higher values in central parts and along the main streams and roadways (Fig. S2).

\subsection{Application models}

The three machine learning models selected to determine the role of factors influencing gully occurrence in the study region were maximum entropy (ME), random forest (RF), and boosted regression trees (BRT).

\subsubsection{Maximum entropy (ME)}

The ME model is based on the principle of maximization, which derives from the concepts of statistical mechanics and information 
(Woodbury et al., 1995). It seeks to select a constraint with the largest entropy among all probabilities of a given constraint (Woodbury et al., 1995). In this study, the gully erosion distribution was defined as a probability distribution in ME by assigning different weights to their location (X) in the study region, calculated as (Park, 2015):

$P(y=1 \mid x)=\frac{P(y=1) P(x \mid y=1)}{P(x)}=\frac{P(y=1) \pi(x)}{1 /|X|}$

where $P(y=1)$ is the probability of occurrence of gully erosion, and $|X|$ is the area (number of pixels) of events occurring in the study region. In addition, $x$ denotes a random site over the study region. The $\pi(x)$ required by the ME model is similar to the estimate of Gibbs probability distribution function (Phillips and Dudík, 2008). If $n$ features are assumed in the model $\left(f_{i}, i=1, \ldots, n\right)$, the Gibbs probability distribution can be written as (Park, 2015):

$q_{\lambda}(x)=\frac{\exp \left(\sum_{i=1}^{n} \lambda_{i} f_{i}(x)\right)}{Z_{\lambda}}$

where $Z_{\lambda}$ is the normalization constant, and $\lambda$ is the sum of the vector weights assigned to the features. The ME model searches for the Gibbs distribution function that could maximize the log-likelihood of probability and minimize the estimation error. Assuming that $m$ events have occurred in the study region, the difference between the log-likelihood calculation and regularization is maximized using the following equation (Phillips and Dudík, 2008):

$\frac{1}{m} \sum_{i=1}^{m} \ln \left(q \lambda\left(X_{i}\right)\right)-\sum_{j=i}^{n} \beta_{j}\left|\lambda_{i}\right|$

where $\beta_{\mathrm{j}}$ is the normalized parameter. The first term in equation (3) is used for the maximum degree of fitting model value and the second term is used for normalization of the value. Each conditioning factor used in the ME model has a response curve (Hosseini et al., 2013). In addition, the jackknife experiment is often used to rank the importance of each condition factor in ME modeling (Zweig and Campbell, 1993). This is a cross-validation method that can assess the accuracy of each predictor in the model (Phillips et al., 2006).

\subsubsection{Random forest (RF)}

The RF model considers a set of $n$ trees (forest) to improve efficiency and predictability (Breiman, 2001). This model is often used to solve multiple problems related to classification and prediction issues (Trigila et al., 2015). Compared with classification and regression tree methods, the RF model reduces the effects of the two deficiencies that are sensitive to training data and have a limited number of nodes (Breiman, 2001). The training dataset of the model is selected using bagging technology to select random variable samples and observations at each node of the tree. However, randomly selecting the training dataset will have a certain impact on the results of the model. Therefore, a large number of trees are preferentially selected to ensure the stability of the model.

One of the advantages of RF is dealing with a large number of related variables without reducing the prediction accuracy. A disadvantage is that the resulting model may be difficult to interpret, which makes it particularly important to choose the most important variables (Hollister et al., 2016). Previous studies have shown that percentage mean squared error increase can be used to rank variables and select the most important variables (Nasielski et al., 2020). Using this method, a minimum set of variables can be obtained to maximize the accuracy of the model.

\subsubsection{Boosted regression tree (BRT)}

The BRT model with stochastic gradient boosting can give faster and more accurate calculations through numerical optimization (Friedman, 2001). The BRT model is a statistical model based on two powerful programs including regression trees and boosting (Müller et al., 2013).
The function of the regression tree is to divide the prediction space into several mutually exclusive areas, where each divided area contains a set of decision rules. Fig. S3 demonstrates the process using an inverted tree structure with roots at the top and leaves at the bottom (Kashani and Mohaymany, 2011). As one of the classifiers with the lowest error rate, the booster can combine the predictions of some models that do not have strong predictions to provide a robust result, thereby improving the accuracy of the model (Saha et al., 2015).

The advantages of the BRT model are that: (i) it can accommodate different types of predictors and missing values at the same time; (ii) it is immune to the effects of extreme outliers and uncorrelated predictors; and (iii) it has the ability to fit between-predictor interaction (Leathwick et al., 2006).

\subsection{Accuracy assessment}

Evaluating the accuracy of model outputs is one of the steps directly affecting application of a given model, soil conservation measures, and land use planning. Accuracy can be assessed using different statistical evaluation metrics based on comparing observed date to predicted values in model outputs (Frattini et al., 2010). Evaluation metrics can be classified as cutoff-dependent and cutoff-independent. In this study, receiver operating characteristic (ROC) curve was selected as it is the most robust cutoff-independent metric. Area under the ROC curve (AUC) is a quantitative metric that shows the accuracy of models. True skill statistic (TSS), which is cutoff-dependent, was selected as the secondary evaluation metric in assessment of model accuracy. Both AUC and TSS are calculated using four elements: hits $\left(H_{t}\right)$, correct rejections $\left(C_{t}\right)$, false alarms $\left(F_{t}\right)$, and misses $\left(M_{t}\right)$. In this study, $H_{t}$ indicated the number of gully occurrences correctly predicted by the model $(+\mid+) ; C_{t}$ was the number of non-gully locations that the model predicted as low gully erosion susceptibility (-|-); $F_{t}$ was the number of non-gullies that the model erroneously classified as gully erosion susceptibility area $(-\mid+)$; and $M_{t}$, the converse of $F_{t}$, indicated the number of gullies that the model erroneously predicted as safe area $(+\mid-)$. TSS and AUC were calculated using the following equations:

$$
\begin{aligned}
& T S S=\frac{H_{t}}{H_{t}+M_{t}}-\frac{F_{t}}{F_{t}+C_{t}} \\
& A U C=\int_{0}^{1} f\left(F_{t}\right) d f F_{t}=1-\int_{0}^{1} f\left(C_{t}\right) d C_{t}
\end{aligned}
$$

The value of AUC metric can be classified: AUC $<0.7$ (unacceptable), $0.7<$ AUC $<0.8$ (good), $0.8<$ AUC $<0.9$ (very good), $0.9<$ AUC $<1$ (excellent) (Rahmati et al., 2017). All three models were evaluated and their accuracy in the training and validation phases were assessed. The best model of the three (based on AUC and TSS metrics) prioritizes soil erosion measures and land use management programs. The best model was then used to conduct the relative importance of variable (RIV) analysis, identifying the most important causative factors. In order to calculate the RIV index, each causative factor should be excluded from the modeling and the associated accuracy of the model is then evaluated using the AUC metric. This step is repeated for all causative factors and the accuracy of the model in each step are compared with the accuracy of the model when all causative factors contributed to the modeling process. This method also termed as removal sensitivity analysis. The accuracy of the model is generally reduced when a causative factor is excluded and the reduction is proportional to the importance of the causative factor: more reduction in model accuracy, more importance of causative factor.

\section{Results}

\subsection{Performance of models}

The ROC curves of the models in the training and validation steps are 

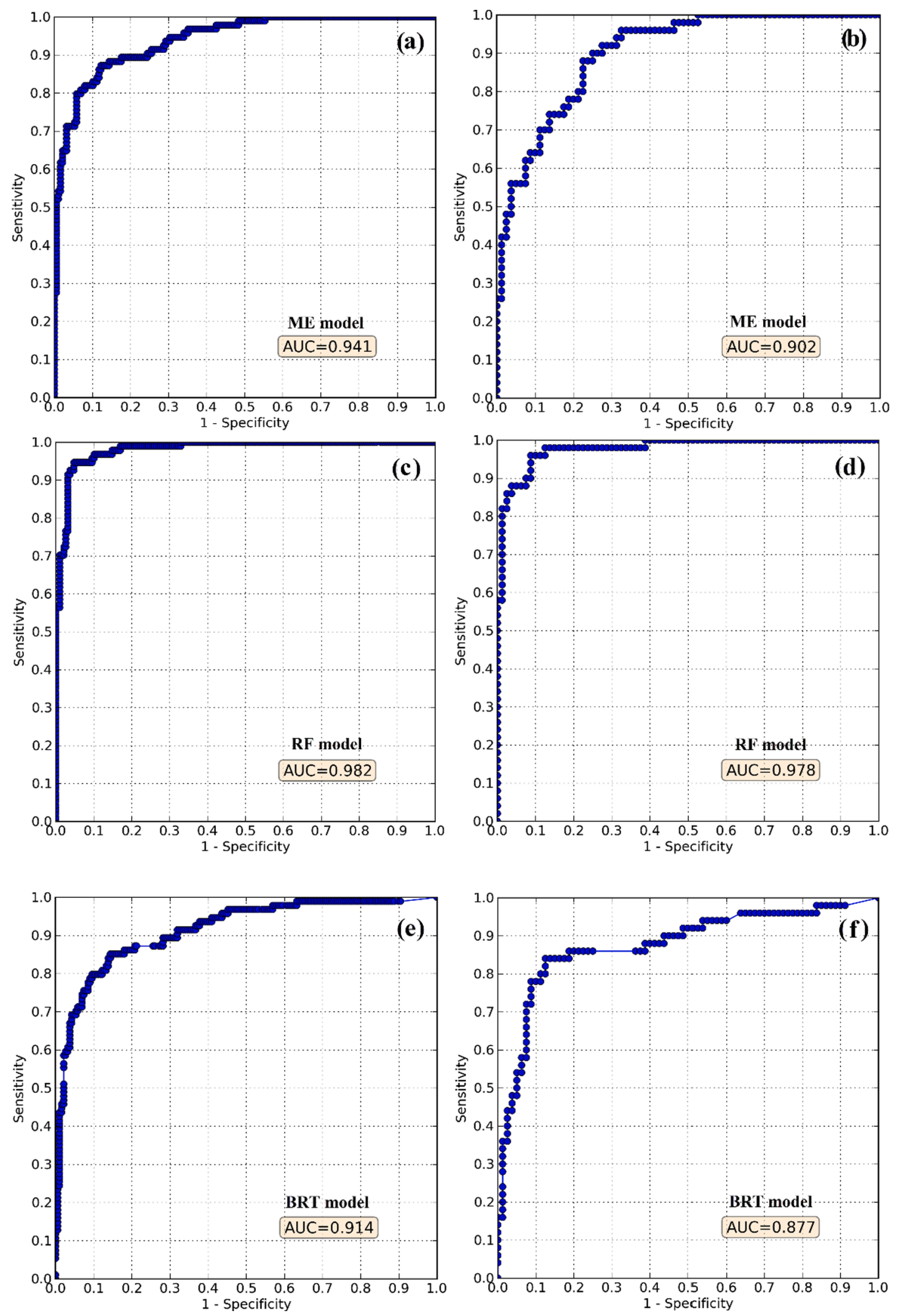

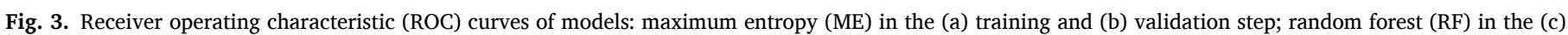
training and (d) validation step; and boosted regression trees (BRT) in the (e) training and (f) validation step. 
Table 1

Accuracy of the models based on TSS and AUC.

\begin{tabular}{lllll}
\hline Evaluation metric & Modeling step & \multicolumn{2}{l}{ Models } & \\
\cline { 3 - 5 } & & ME & RF & BRT \\
\hline True skill statistic (TSS) & Training & 0.922 & 0.969 & 0.893 \\
& Validation & 0.870 & 0.962 & 0.862 \\
Area under the ROC curve (AUC) & Training & 0.941 & 0.982 & 0.914 \\
& Validation & 0.902 & 0.978 & 0.877 \\
\hline
\end{tabular}

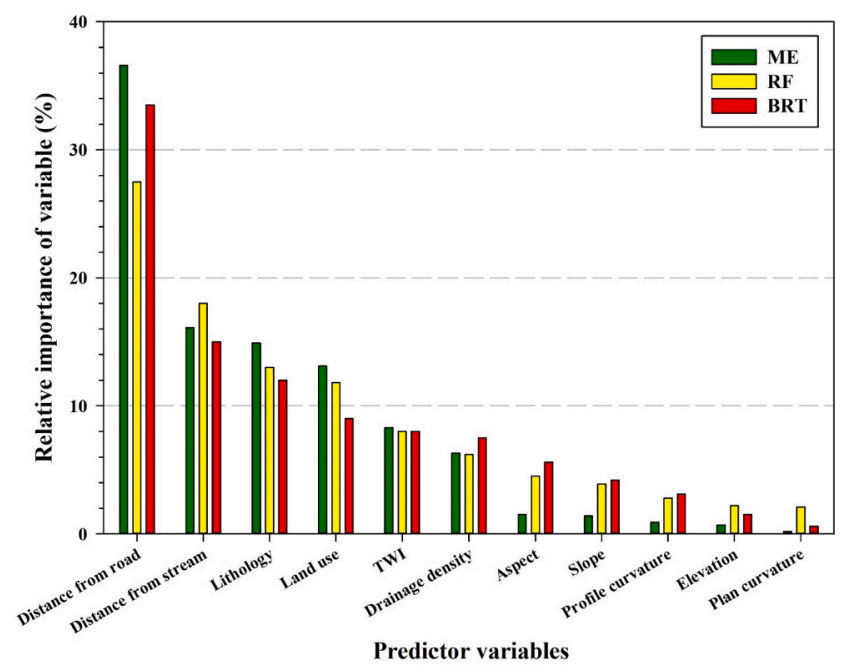

Fig. 4. Relative importance of variables (RIV) based on the random forest (RF), boosted regression trees (BRT), and maximum entropy (ME) models. TWI = topographic wetness index.

shown in Fig. 3. The AUC results for each ROC curve indicated that RF gave the best goodness-of-fit (training phase) and predictive skill (validation phase), with AUC values of 0.982 and 0.978 , respectively. The accuracy assessment of the BRT model indicated that it has the lowest performance, with an AUC value of 0.914 in the training step and 0.877 in the validation step. For the ME model, the AUC value was 0.941 in the training step and 0.902 in the validation step. It should be noted that the accuracy of the models in the training step could not be used to assess their prediction capability, because the training dataset was used to calibrate the models. The validation AUC values illustrated how well the models predicted gully erosion for a given area, and RF was the best model, followed by ME and BRT. The predictive performance of the models was classified as excellent for RF (AUC > 0.9) and ME (AUC > $0.9)$, and very good for BRT $(0.9>$ AUC $>0.8)$.

According to the TSS metric, in the training step the RF model had the highest goodness-of-fit (TSS $=0.969$ ), followed by ME (TSS = 0.922), and BRT (TSS $=0.893$ ) (Table 1 ). In the validation step, RF was again the best model in terms of predictive performance (TSS $=0.962$ ), followed by ME (TSS $=0.87$ ) and BRT (TSS $=0.862$ ). Therefore, the TSS metric confirmed the results obtained with the ROC approach.

\subsection{Relative importance of factors determining gully erosion}

The results of RIV analysis based on all three models are shown in Fig. 4. Distance from road $\left(\mathrm{RIV}_{\mathrm{RF}}=27 \%, \mathrm{RIV}_{\mathrm{ME}}=36.3 \%, \mathrm{RIV}_{\mathrm{BRT}}=\right.$ $33.8 \%$ ) was the most influential factor for all models. Distance from stream $\left(\mathrm{RIV}_{\mathrm{RF}}=18 \%, \mathrm{RIV}_{\mathrm{ME}}=16.1 \%, \mathrm{RIV}_{\mathrm{BRT}}=14.7 \%\right)$, lithology $\left(\mathrm{RIV}_{\mathrm{RF}}=13.2 \%, \mathrm{RIV}_{\mathrm{ME}}=14.5 \%, \mathrm{RIV}_{\mathrm{BRT}}=12.3 \%\right)$, and land use $\left(\mathrm{RIV}_{\mathrm{RF}}\right.$ $\left.=12.1 \%, \mathrm{RIV}_{\mathrm{ME}}=12.8 \%, \mathrm{RIV}_{\mathrm{BRT}}=8 \%\right)$ made a medium contribution (RIV $=10-20 \%$ ) to gully erosion occurrence process. The other factors showed lower relative importance (RIV $<10 \%$ ) in the order: TWI $>$ drainage density $>$ aspect $>$ slope $>$ profile curvature $>$ elevation $>$ plan curvature. However, it should be highlighted that gully occurrence is a complicated process and all factors contributed to improve the predictive performance of the models.

Fig. 5 illustrates the response curves of the continuous variables applied for modeling gully erosion susceptibility. The response curve of elevation showed the highest probability for forming gully erosion at $450 \mathrm{~m}$ (Fig. 5a). With increasing elevation ( $>450 \mathrm{~m}$ ), the probability of gullying gradually decreased. Slope factor had an inverse relationship with the probability of gully occurrence, with the maximum contribution found in flat surfaces (Fig. 5b). Since the soil layer on steeper slopes is often thinner and hence insufficient for the piping process that initiates gully formation. Both plan and profile curvature indicated the highest probability of gullying in flat areas (plan and profile curvature values near zero) (Fig. 5c, 5d). Concave and convex curvatures showed the lowest contribution to the gully erosion process. Areas close to streams had the highest gully erosion susceptibility, probably due to surface water convergence, and gully erosion probability decreased with distance from stream (Fig. 5e). Increasing drainage density led to a rapid increase in gully erosion susceptibility (Fig. 5f). Higher drainage density causes a rapid hydrological response, and thus the potential for gully erosion and sediment transport can increase. An increase in TWI also led to an increase in gully erosion susceptibility (Fig. 5g), since high TWI values represent a large contributing area upstream and more runoff potential. We found a maximum contribution from distance from road of about $10 \mathrm{~m}$, indicating the role of water concentration provided by roadside culverts (Fig. $5 \mathrm{~h}$ ).

\subsection{Gully erosion susceptibility mapping}

Gully susceptibility maps for the study region were created using the ME, RF, and BRT models (Fig. S4). The overall spatial patterns of gully erosion susceptibility in all models were similar, although the details of gully erosion susceptibility maps were different. According to RF as the best model based on AUC and TSS evaluation metrics, locations along the main stream and the road network were the most susceptible areas to gully erosion in the study region, where rural areas and associated human activities are also centered. These areas did not have a steep slope, but had high TWI values. In addition, mountainous areas were predicted to have the lowest susceptibility to gully erosion.

Applying an equal interval classification scheme, the susceptibility values for gully erosion produced by the three models were grouped into five classes from 'very low' to 'very high'. These classes were applied to create gully erosion susceptibility maps based on the model results (Fig. 6). The latter were mainly associated with low elevation areas where the main streams and roads are located, with high values of TWI and almost zero curvature.

The relative distribution of classes of gully erosion susceptibility is illustrated in Fig. S5. For the ME model, the area allocation to very low, low, medium, high, and very high susceptibility classes were estimated as $84.39 \%, 10.59 \%, 3.79 \%, 1.03 \%$, and $0.18 \%$, respectively. For the RF model, in total $64.86 \%$ of the study region was classified under the very low and low susceptibility classes, whereas $12.39 \%$ and $12.41 \%$ of the study region were associated with high and very high susceptibility classes. According to the results of BRT model, 29.62\%, $13.74 \%$, $23.35 \%, 14.91 \%$, and $18.35 \%$ of the study region fell into very low, low, medium, high, and very high susceptibility classes, respectively. As can be seen, the ME model recognized only $1.21 \%$ (in total) as related to high and very high susceptibility zones, while the corresponding value based on the BRT model was in total $32.8 \%$ of the study region. The RF model had a balanced behavior for gully susceptibility values and classification of area in terms of gully susceptibility zones. 

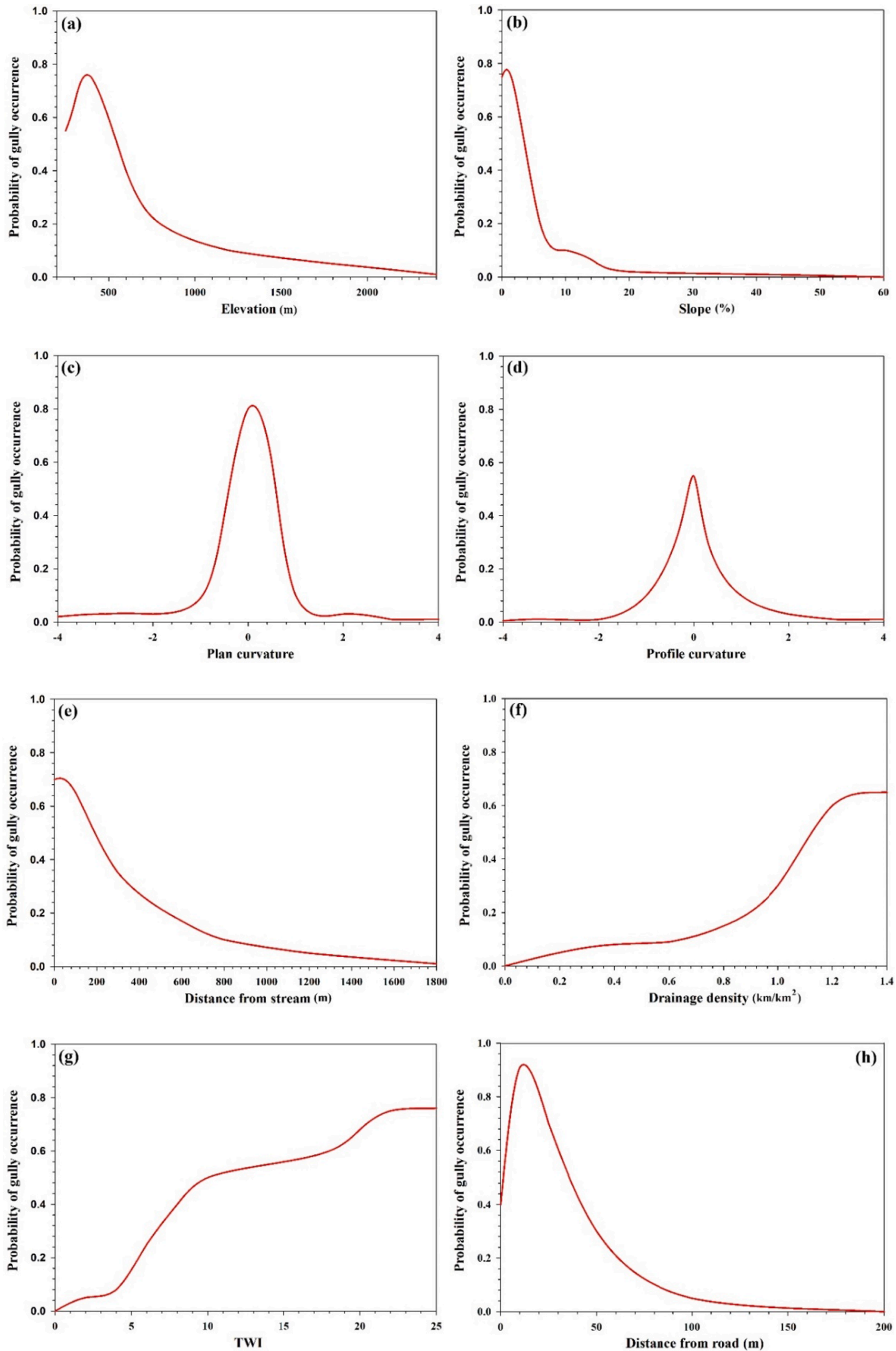

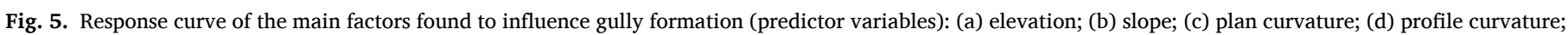
(e) distance from stream; (f) drainage density, (g) topographic wetness index (TWI) and (h) distance from road. 

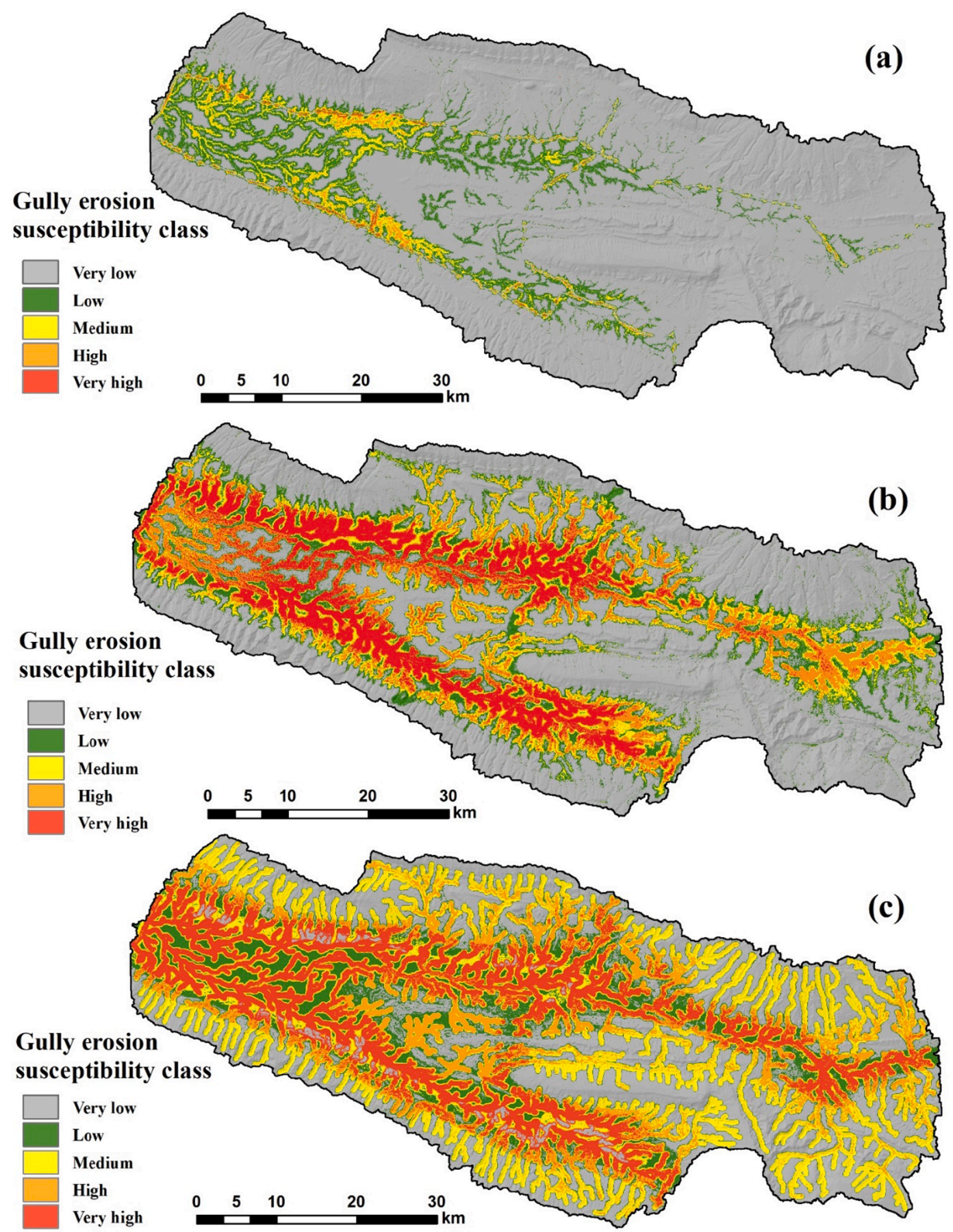

Fig. 6. Classified maps of gully erosion susceptibility created for the: (a) maximum entropy (ME), (b) random forest (RF), and (c) boosted regression tree (BRT) models.

\section{Discussion}

\subsection{Role of gully conditioning factors}

Soil erosion is the outcome of interactions between several influencing factors, including runoff characteristics, soil erodibility, and human impact (Malik, 2008). Results of this study clearly indicated that proximity to roads is associated with increased susceptibility to gully formation. Road construction in vulnerable arid and semi-arid regions requires appropriate engineering measures that consider site conditions, as otherwise it can have adverse environmental impacts which frequently include gully erosion (Rizeei et al., 2018). Result also confirmed the findings of Zhang et al. (2019) research that assessed the road construction impact on gully erosion occurrences. For interpreting influence and interaction between road construction and gully erosion occurrence, Nyssen et al. (2002) compared topographic thresholds of 'natural' gullies and for gullies induced by road construction and demonstrated that gully induced by road building had lower topographic thresholds in comparison with natural gully heads (without road impacts). The importance of transportation networks in this study reasons that sustainable land management cannot be achieved without completely accounting for the influence of road construction on soil erosion. As discussed by Arnaez et al. (2004), roads often impede infiltration and also concentrate surface runoff with enough energy, 
resulting in occurring different erosion types. The results also are in line with the findings of Galia et al. (2017) that splashing on the compacted roadbed and roadsides is unable to detach the particles but concentrated runoff can rapidly cause gullies in downstream sites, especially where culverts release water onto unprotected and steep slopes.

In this study, distance from streams was also identified as an influential factor for erosion occurrence, and significantly contributed to predicted gully erosion potential. In general, short distance to stream resulted in higher potential for gully erosion occurrence and development within this study region, because concentrated surface runoff act as a soil erosion driver. Development and socio-economic benefits in rural areas are conditional on the existence and quality of infrastructure to connect them to the other parts of country.

\subsection{Gully erosion susceptibility prediction}

According to Conoscenti et al. (2013), susceptibility modeling of gully erosion provides useful information for better understanding of erosion mechanisms supporting further sustainability by enabling efficient control measures. Susceptibility erosion maps based on the RF model (as the best model for the region researched in this study) could be suitable in identifying fully susceptible areas. Once know, measures to prevent gully erosion initiation in arid and semi-arid regions may be employed. Therefore, gully erosion susceptibility assessment should be identified as an important fundamental step toward evaluating areas prone to gully erosion. All gully erosion susceptibility maps produced in the study region showed excellent functionality for mapping of erosion sensitivity with all identifying the most effective factors as distance from roads and streams, parent material, and land use, followed by TWI, drainage intensity, and aspect. Based on modelling results, RF is more precise compared to BRT and ME in mapping sensitivity to gully erosion. The RF model explains the spatial relation between gullies and dominant contributing factors, based on multiple decision trees that were merged together. This result is in agreement with the results of Gayen and Pourghasemi (2019). Gully susceptibility maps generated for the study region will be useful to decision makers, particularly when allocating conservation resources as well as suggesting prevention measures for gully erosion. Sustainable land use planning and land practices are important for prevention or control of runoff. Identifying synergies between land degradation and sustainable environmental transformation is fundamental for different land-related stakeholders. Finally, use of modern machine learning techniques and accurate gully erosion inventory, can provide robust gully erosion susceptibility maps, as a baseline for sustainable land use planning (Kalantari et al., 2019b). Our study provided strong evidence that some parts of the study region belong to high and very high susceptible zones and need serious land management.

\section{Conclusions}

Intensive gully erosion development in arid and semi-arid regions underpin the need for conducting research to investigate how human activities and geo-environmental factors affect gully erosion occurrence. In this study, three state-of-the-art models (ME, RF, BRT) were used to address this research gap. The accuracy of the models and their gully susceptibility maps were evaluated using AUC and TSS metrics. The following conclusions can be drawn from this study.

- All three models clearly identified distance from roads (i.e., proximity to roads) as having the highest relative importance for gully erosion occurrence in this study region. Results showed that location of culverts and drainage ditches are crucial factors in the spatial pattern of gully features in the study region. Although growing road networks support local travel, tourism, and agricultural development, it creates problems associated with gully erosion and sediment production. Distance from road is followed by distance from stream, lithology, and land use. Other factors showed medium or weak contribution in the modeling process. National organizations, local governments, and non-governmental organizations should consider the results for controlling gully erosion.

- Analysis of the accuracy of gully erosion susceptibility maps generated using the three models indicated that RF was the best model (AUC $=0.978$, TSS $=0.962$ ), followed by ME (AUC $=0.902$, TSS $=$ 0.87 ) and BRT (AUC $=0.877$, TSS $=0.862$ ). The precise gully erosion map produced by RF can thus be used as a guidance for soil conservation and land management.

\section{Declaration of Competing Interest}

The authors declare that they have no known competing financial interests or personal relationships that could have appeared to influence the work reported in this paper.

\section{Acknowledgments}

We thank the Iranian Department of Water Resources Management (IDWRM) in Ministry of Energy for providing geo-environmental and basic maps. We highly appreciate anonymous reviewers for their constructive comments and valuable suggestions that helped us to improve the manuscript.

\section{Appendix A. Supplementary data}

Supplementary data to this article can be found online at https://doi. org/10.1016/j.catena.2021.105925.

\section{References}

Arnáez, J., Larrea, V., Ortigosa, L., 2004. Surface runoff and soil erosion on unpaved forest roads from rainfall simulation tests in northeastern Spain. Catena 57 (1), 1-14. Bergonse, R., Reis, E., 2016. Controlling factors of the size and location of large gully systems: A regression-based exploration using reconstructed pre-erosion topography. Catena 147, 621-631.

Bewket, W., Sterk, G., 2003. Assessment of soil erosion in cultivated fields using a survey methodology for rills in the Chemoga watershed, Ethiopia. Agric. Ecosyst. Environ. 97 (1-3), 81-93.

Breiman, L., 2001. Random forests. Machine Learning 45 (1), 5-32.

Castillo, C., Gómez, J.A., 2016. A century of gully erosion research: Urgency, complexity and study approaches. Earth Sci. Rev. 160, 300-319.

Conoscenti, C., Agnesi, V., Angileri, S., Cappadonia, C., Rotigliano, E., Märker, M., 2013. A GIS-based approach for gully erosion susceptibility modelling: a test in Sicily, Italy. Environ. Earth Sci. 70 (3), 1179-1195.

Conoscenti, C., Angileri, S., Cappadonia, C., Rotigliano, E., Agnesi, V., Märker, M., 2014. Gully erosion susceptibility assessment by means of GIS-based logistic regression: a case of Sicily (Italy). Geomorphology 204, 399-411.

Croke, J., Mockler, S., 2001. Gully initiation and road-to-stream linkage in a forested catchment, southeastern Australia. Earth Surf. Proc. Land. 26 (2), 205-217.

Derose, R.C., Gomez, B., Marden, M., Trustrum, N.A., 1998. Gully erosion in Mangatu forest, New Zealand, estimated from digital elevation models. Earth Surf. Proc. Land. 23 (11), 1045-1053.

Fox, G.A., Sheshukov, A., Cruse, R., Kolar, R.L., Guertault, L., Gesch, K.R., Dutnell, R.C., 2016. Reservoir sedimentation and upstream sediment sources: perspectives and future research needs on streambank and gully erosion. Environ. Manage. 57 (5), 945-955.

Frattini, P., Crosta, G., Carrara, A., 2010. Techniques for evaluating the performance of landslide susceptibility models. Eng. Geol. 111 (1-4), 62-72.

Friedman, J.H., 2001. Greedy function approximation: a gradient boosting machine. Ann. Stat. 1189-1232.

Galang, M.A., Morris, L.A., Markewitz, D., Jackson, C.R., Carter, E.A., 2010. Prescribed burning effects on the hydrologic behavior of gullies in the South Carolina Piedmont. Forest Ecol. Manage. 259 (10), 1959-1970.

Galia, T., Šilhán, K., Škarpich, V., 2017. The geomorphic impacts of culverts at paved forest roads: Examples from Carpathian headwater channels, Czech Republic. Catena 157, 424-435.

Garosi, Y., Sheklabadi, M., Pourghasemi, H.R., Besalatpour, A.A., Conoscenti, C., Van Oost, K., 2018. Comparison of differences in resolution and sources of controlling factors for gully erosion susceptibility mapping. Geoderma 330, 65-78.

Gayen, A., Pourghasemi, H.R., 2019. Spatial modeling of gully erosion: a new ensemble 697 of CART and GLM data-mining algorithms. In: Spatial Modeling in GIS and R for Earth and 698 Environmental Sciences. Elsevier, 653-669. https://doi.org/10.1016/ B978-0-12-815226-699 3.00030-2. 
Gholami, V., 2013. The influence of deforestation on runoff generation and soil erosion (Case study: kasilian Watershed). J. Forest Sci. 59 (No. 7), 272-278.

Gómez-Gutiérrez, Á., Conoscenti, C., Angileri, S.E., Rotigliano, E., Schnabel, S., 2015. Using topographical attributes to evaluate gully erosion proneness (susceptibility) in two mediterranean basins: Advantages and limitations. Nat. Hazards 79 (S1), 291-314.

Guerra, A.J.T., 2004. Gully erosion monitoring in Sa'o Luis City, Maran ha'o state, Brazil. In: Li, Y., Poesen, J., Valentin, C. (Eds.), Gully Erosion Under Global Change. Sichuan Science and Technology Press, Chengdu, China, 13- 20.

Hassen, G., Bantider, A., 2020. Assessment of drivers and dynamics of gully erosion in case of Tabota Koromo and Koromo Danshe watersheds, South Central Ethiopia. Geoenviron. Disasters 7, Art. 5. https://doi.org/10.1186/s40677-019-0138-4.

Hollister, J.W., Milstead, W.B., Kreakie, B.J., Peters, D.P.C., 2016. Modeling lake trophic state: a random forest approach. Ecosphere 7 (3). https://doi.org/10.1002/ ecs 2.1321.

Hosseini, S.Z., Kappas, M., Zare Chahouki, M.A., Gerold, G., Erasmi, S., Rafiei Emam, A., 2013. Modelling potential habitats for Artemisia sieberi and Artemisia aucheri in Poshtkouh area, central Iran using the maximum entropy model and geostatistics. Ecol. Inf. 18, 61-68.

Makanzu Imwangana, F., Dewitte, O., Ntombi, M., Moeyersons, J., 2014. Topographic and road control of mega-gullies in Kinshasa (DR Congo). Geomorphology 217, 131-139.

Kalantari, Z., Ferreira, C.S.S., Page, J., Goldenberg, R., Olsson, J., Destouni, G., 2019. Meeting sustainable development challenges in growing cities: Coupled socialecological systems modeling of land use and water changes. J. Environ. Manage. 245, 471-480. https://doi.org/10.1016/j.jenvman.2019.05.086.

Kashani, A.T., Mohaymany, A.S., 2011. Analysis of the traffic injury severity on two-lane, two-way rural roads based on classification tree models. Saf. Sci. 49 (10), 1314-1320.

Kheir, R.B., Wilson, J., Deng, Y., 2007. Use of terrain variables for mapping gully erosion susceptibility in Lebanon. Earth Surf Process Landf 32 (12), 1770-1782.

Leathwick, J.R., Elith, J., Francis, M.P., Hastie, T., Taylor, P., 2006. Variation in demersa fish species richness in the oceans surrounding New Zealand: an analysis using boosted regression trees. Mar. Ecol. Prog. Ser. 321, 267-281.

Lesschen, J.P., Kok, K., Verburg, P.H., Cammeraat, L.H., 2007. Identification of vulnerable areas for gully erosion under diferente scenarios of land abandonment in Southeast Spain. Catena 71, 110-121.

Lucà, F., Conforti, M., Robustelli, G., 2011. Comparison of GIS-based gullying susceptibility mapping using bivariate and multivariate statistics: Northern Calabria, South Italy. Geomorphology 134 (3-4), 297-308.

Malik, I., 2008. Dating of small gully formation and establishing erosion rates in old gullies under forest by means of anatomical changes in exposed tree roots (Southern Poland). Geomorphology 93 (3-4), 421-436.

Mararakanye, N., Sumner, P.D., 2017. Gully erosion: A comparison of contributing factors in two catchments in South Africa. Geomorphology 288, 99-110.

Martínez-Casasnovas, J.A., Ramos, M.C., Ribes-Dasi, M., 2002. Soil erosion caused by extreme rainfall events: mapping and quantification in agricultural plots from very detailed digital elevation models. Geoderma 105 (1-2), 125-140.

Mea, 2005. Millennium Ecosystem Assesment: Ecosystems and Human Well-Being: Desertification Synthesis. World Resource Institute, Washington D.C.

Moeini, A., Zarandi, N.K., Pazira, E., Badiollahi, Y., 2015. The relationship between drainage density and soil erosion rate: A study of five watersheds in Ardebil Province, Iran. In: Mambretti, S., Melgarejo, J. (Eds.), River Basin Management. WIT Transactions on Ecology and The Environment, vol 197. WIT Press, Southampton, United Kingdem.

Müller, D., Leit o, P.J., Sikor, T., 2013. Comparing the determinants of cropland abandonment in Albania and Romania using boosted regression trees. Agricultural Systems, 117, 66-77.

Nasielski, J., Earl, H., Deen, B., 2020. Which plant traits are most strongly related to postsilking nitrogen uptake in maize under water and/or nitrogen stress? J. Plant Physiol. 244, 153059.

Nefeslioglu, H.A., Duman, T.Y., Durmaz, S., 2008. Landslide susceptibility mapping for a part of tectonic Kelkit Valley (Eastern Black Sea region of Turkey). Geomorphology 94, 401-418.

Nyssen, J., Poesen, J., Moeyersons, J., Luyten, E., Veyret-Picot, M., Deckers, J., Haile, M., Govers, G., 2002. Impact of road building on gully erosion risk: a case study from the Northern Ethiopian Highlands. Earth Surf. Process. Landforms 27, 1267-1283.

Oygarden, L., 2003. Rill and gully development during an extreme winter runoff event in Norway. Catena 50, 217-242.
Park, N.W., 2015. Using maximum entropy modeling for landslide susceptibility mapping with multiple geoenvironmental data sets. Environ. Earth Sci. 73 (3), 937-949.

Peter, K.D., d'Oleire-Oltmanns, S., Ries, J.B., Marzolff, I., Hssaine, A.A., 2014. Soil erosion in gully catchments affected by land-levelling measures in the Souss Basin, Morocco, analysed by rainfall simulation and UAV remote sensing data. Catena 113, 24-40.

Phillips, S.J., Anderson, R.P., Schapire, R.E., 2006. Maximum entropy modeling of species geographic distributions. Ecol. Model. 190 (3-4), 231-259.

Phillips, S.J., Dudík, M., 2008. Modeling of species distributions with Maxent: new extensions and a comprehensive evaluation. Ecography 31 (2), 161-175.

Planchon, O., Fritsch, E., Valentin, C., 1987. Rill development in a wet savannah environment. Catena. Supplement 8, 55-70.

Radula, M.W., Szymura, T.H., Szymura, M., 2018. Topographic wetness index explains soil moisture better than bioindication with Ellenberg's indicator values. Ecol. Ind. $85,172-179$.

Rahmati, O., Tahmasebipour, N., Haghizadeh, A., Pourghasemi, H.R., Feizizadeh, B., 2017. Evaluating the influence of geo-environmental factors on gully erosion in a semi-arid region of Iran: An integrated framework. Sci. Total Environ. 579, 913-927.

Rizeei, H.M., Pradhan, B., Saharkhiz, M.A., 2018. An integrated fluvial and flash pluvial model using 2D highresolution sub-grid and particle swarm optimization-based random forest approaches in GIS. Complex Intell. Syst. 1-20 https://doi.org/ 10.1007/s40747-018-0078-8.

Saha, D., Alluri, P., Gan, A., 2015. Prioritizing Highway Safety Manuali ${ }^{-}$s crash prediction variables using boosted regression trees. Accid. Anal. Prev. 79, 133-144.

Samani, A.N., Ahmadi, H., Mohammadi, A., Ghoddousi, J., Salajegheh, A., Boggs, G., Pishyar, R., 2010. Factors controlling gully advancement and models evaluation (Hableh Rood Basin, Iran). Water Resour. Manage. 24 (8), 1531-1549.

Seutloali, K.E., Beckedahl, H.R., Dube, T., Sibanda, M., 2016. An assessment of gully erosion along major armoured roads in south-eastern region of South Africa: A remote sensing and GIS approach. Geocarto Int. J. 31 (2), 225-239.

Shellberg, J.G., Spencer, J., Brooks, A.P., Pietsch, T.J., 2016. Degradation of the Mitchell River fluvial megafan by alluvial gully erosion increased by post-European land use change, Queensland, Australia. Geomorphology 266, 105-120.

Suman, S., Khan, S.Z., Das, S.K., Chand, S.K., 2016. Slope stability analysis using artificial intelligence techniques. Nat. Hazard. 84 (2), 727-748.

Trigila, A., Iadanza, C., Esposito, C., Scarascia-Mugnozza, G., 2015. Comparison of Logistic Regression and Random Forests techniques for shallow landslide susceptibility assessment in Giampilieri (NE Sicily, Italy). Geomorphology 249, 119-136.

Valentin, C., 2004 Overland flow, erosion and associated sediment and biogeochemical transports. P. Kabat, M. Claussen, P.A. Dirmeyer, J.H.C. Gash, L. Bravo de Guenni, M. Meybeck, R.A. Pielke Sr, C.J. Vörösmarty, R.W.A. Hutjes, S. Lütkemeier (Eds.), Vegetation, Water, Humans and the Climate. A New Perspective on an Interactive System, Springer Verlag, Berlin (2004), 317-322. Global Change-The IGBP Series, 2003.

Valentin, C., Poesen, J., Li, Y., 2005. Gully erosion: Impacts, factors and control. Catena 63, 132-153.

Vanwalleghem, T., Gómez, J.A., Amate, J.I., de Molina, M.G., Vanderlinden, K., Guzmán, G., Laguna, A., Giráldez, J.V., 2017. Impact of historical land use and soil management change on soil erosion and agricultural sustainability during the Anthropocene. Anthropocene 17, 13-29.

Wang, J., Wei, H., Cheng, K., Ochir, A., Davaasuren, D., Li, P., Chan, F.K.S., Nasanbat, E., 2020. Spatio-temporal pattern of land degradation from 1990 to 2015 in Mongolia. Environ. Dev. 34, 100497.

Wilson, J.P., Gallant, J.C., 2000. Terrain Analysis Principles and Applications. Wiley, Toronto, Canada.

Woodbury, A., Render, F., Ulrych, T., 1995. Practical probabilistic ground-water modeling. Groundwater 33 (4), 532-538.

Zhang, Y., Zhao, Y., Liu, B., Wang, Z., Zhang, S., 2019. Rill and gully erosion on unpaved roads under heavy rainfall in agricultural watersheds on China's Loess Plateau. Agric. Ecosyst. Environ. 284, 106580.

Zhao, G., Mu, X., Wen, Z., Wang, F., Gao, P., 2013. Soil erosion, conservation, and ecoenvironment changes in the Loess Plateau of China. Land Degrad. Dev. 24 (5), 499-510.

Zhu, H.D., Shi, Z.H., Fang, N.F., Wu, G.L., Guo, Z.L., Zhang, Y., 2014. Soil moisture response to environmental factors following precipitation events in a small catchment. Catena 120, 73-78.

Zweig, M.H., Campbell, G., 1993. Receiver-operating characteristic (ROC) plots: a fundamental evaluation tool in clinical medicine. Clin. Chem. 39 (4), 561-577. 